\section{Epidural epinephrine and the systemic circulation during peripheral vascular surgery}

Frederick C. Salevsky BSc MSc MD FRCPC, David G. Whalley MB ChB FFARCS FRCPC, David Kalant BSc, J. Crawhall MD PhD FRCP FRCPC
This study was designed to determine the haemodynamic effects of epidural epinephrine, $5 \mu \mathrm{g} \cdot \mathrm{ml}^{-1}$, added to bupivacaine, 0.75 per cent, in elderly patients with cardiac disease undergoing peripheral vascular surgery (PVS). The effect of epidural epinephrine on the plasma concentration of bupivacaine was also measured. Twenty patients with a history andlor ECG evidence of myocardial ischaemia requiring $P V S$ were randomly assigned to two groups. The patients were monitored with a modified VS ECG, oscillometric BP monitor and a PA catheter. After control haemodynamic measurements, $12 \mathrm{ml}$ of bupivacaine, 0.75 per cent, \pm epinephrine, $5 \mu \mathrm{g} \cdot \mathrm{ml}^{-1}$, was injected over five minutes into the epidural space at $L_{3-4}$. Supine haemodynamic measurements were repeated at 15 and $45 \mathrm{~min}$ after injection. At 15 min after epidural injection, compared with control values, patients receiving epidural epinephrine showed a significantly greater decrease in mean blood pressure and systemic vascular resistance, and a significantly greater increase in cardiac output than patients receiving plain epidural bupivacaine $(79.3 \pm 11.6$ per cent vs $94.6 \pm 16.8$ per cent, 61.6 \pm 9.0 vs $91.6 \pm 19.2$ per cent, $130.8 \pm 23$ vs $105 \pm 20.8$ per cent, respectively). These differences were not present at $45 \mathrm{~min}$ after epidural injection. Heart rate was not significantly different between groups at either time. The presence of epidural epinephrine reduced the peak plasma concentration of bupivacaine from $0.86 \pm 0.20100 .64 \pm 0.33 \mu \mathrm{g} \cdot \mathrm{ml}^{-1}$ and increased

\section{Key Words}

ANAESTHESIA: cardiovascular; ANAESTHETIC TECHNIQUES: regional; epidural; ANAESTHETICS, LOCAL: bupivacaine; SYMPATHETIC NERVOUS SYSTEM: pharmacology, epinephrine.

From the Departments of Anaesthesia and Clinical Biochemistry, Royal Victoria Hospital and McGill University, Montreal, Quebec.

Address correspondence to: Dr. F.C. Salevsky, Royal Victoria Hospital, Department of Anaesthesia, 687 Pine Avenue West, Montreal, Quebec H3A 1Al Canada. the time to achieve this concentration from $16.1 \pm 11.2$ to 33.7 $\pm 20.1 \mathrm{~min}$.

Cette étude était conçue afin de déterminer les effets hémodynamiques de $5 \mu \mathrm{g} \cdot \mathrm{ml}^{-1} d^{\prime}$ épinéphrine en épidurale ajouté à la bupivacaïne, 0.75 pour cent, chez les patients âgés atteints de maladie cardiaque et devant subir une chirurgie vasculaire périphérique (PVS). L'effet de l'épinéphrine épidurale sur les concentrations plasmatiques de bupivacaine était aussi mesuré. Vingt patients avec une histoire ellou évidence à l'ECG d'ischémie myocardique requérant une chirurgie vasculaire périphérique ont été randomisés en deux groupes. Les patients furent surveillés avec un électrocardiogramme modifié en VS, une pression artérielle par oscillométrie et un cathéter dans l'artère pulmonaire. Après des mesures hémodynamiques de controle, $12 \mathrm{ml}$ de bupivacaine, 0,75 pour cent, \pm épinéphrine, $5 \mu \mathrm{g} \cdot \mathrm{ml}^{-1}$ a été injecté sur cinq minutes dans l'espace épidural de $L_{3-4}$. Les mesures hémodynamiques ont été répétées à 15 et 45 minutes aprés l'injection. Aprés 15 minutes de l'injection épidurale, comparativement aux valeurs de contrôle, les patients ayant reçu de l'épinéphrine en épidurale ont démontré une plus grande diminution significative dans la pression artérielle moyenne et la résistance vasculaire systémique, et une plus grande augmentation significative du débit cardiaque comparativement aux patients ayant reçu une injection d'épidurale de bupivacaine seule $(79.3 \pm 11,6$ vs $94,6 \pm 16,8$ pour cent, $61,6 \pm 9,0$ vs $91,6 \pm 19,2$ pour cent, $130,8 \pm 23$ vs $105 \pm 20,8$ pour cent, respectivement). Ces différences n'étaient pas présentes 45 minutes après injection épidurale. La fréquence cardiaque n'était pas significativement différente entre les groupes en aucun temps. La présence de l'épinéphrine épidurale a réduit la concentration plasmatique maximale de bupivacaine de $0,86 \pm 0,20, a ̀$ a $0,64 \pm 0,33 \mu \mathrm{g} \cdot \mathrm{ml}^{-1}$ et a augmenté le temps afin d'atteindre cette concentration de $16,1 \pm 11,2$ à $33,7 \pm 20,1 \mathrm{~min}$

Epidural anaesthesia has been used for a number of years for extraabdominal peripheral vascular surgery. Its popularity and convenience have recently been reinforced by 
evidence suggesting greater cardiovascular stability when compared with general anaesthesia. 'Many patients presenting for peripheral vascular surgery have coincidental cardiac disease and the greater disturbances in heart rate and blood pressure associated with general anaesthesia may be detrimental.

The cardiovascular effects of epidural anaesthesia are difficult to determine because of the interaction of numerous factors. ${ }^{2}$ Firstly, the level of sympathetic block induced by the epidural anaesthesia determines the extent of peripheral vasodilatation, the degree of compensatory vasoconstriction above the block, and the extent of cardiac sympathetic involvement. Secondly, the systemic effects of the local anaesthetic may modify cardiovascular function according to the extent of absorption. Thirdly, the effects on the patient may be modified by his medical condition. Finally, the type and concentration of vasoconstrictor added to the epidural solution may produce cardiovascular effects either directly through systemic absorption, or indirectly by altering the character of the epidural block, or by altering the rate of absorption of the local anaesthetic.

It is this last effect that the present study was designed to address. The cardiovascular effects of epidural anaesthesia induced by bupivacaine with epinephrine added were determined in patients undergoing extraabdominal peripheral vascular surgery of the lower limb. In addition, the influence of adding epinephrine to the epidural solution in modifying the systemic uptake of local anaesthetic was assessed.

\section{Methods}

After institutional approval and informed consent, 20 patients were randomly assigned in a double-blind fashion to two groups. All patients had a history of cardiac disease, specifically a clinical history or electrocardiographic evidence of myocardial ischaemia.

Patients were premedicated with their usual cardiac medications together with diazepam 5-10 mg PO one hour before surgery. On arrival in the operating room, a modified V5 ECG was applied and a PA catheter inserted under local anaesthesia. Systemic blood pressure was monitored throughout surgery by an automatic noninvasive blood pressure monitor. (DINAMA Vital Signs Monitor 1846 SX:Critikon, Tampa, FL., 33630).

After control haemodynamic measurements were obtained, the patient sat up and $12 \mathrm{ml}$ of test solution were injected over five minutes into the epidural space at the third lumbar interspace. The test solution consisted of bupivacaine, 0.75 per cent (Group B), or bupivacaine, 0.75 per cent, to which epinephrine, $5 \mu \mathrm{g} \cdot \mathrm{ml}^{-1}$, had been added (Group B + E). The patient was subsequently placed supine and a urinary catheter inserted.
Pulmonary wedge pressure and CVP were maintained throughout surgery at their control values with an infusion of Ringer's lactate solution and the haemodynamic measurements were repeated at 15 and $45 \mathrm{~min}$ after epidural injection.

The cephalic spread of anaesthesia, and the time taken to achieve it, were determined by loss of sensation to pin prick. The volume of Ringer's lactate infused, together with the intraoperative blood loss and urine output were recorded throughout surgery.

Plasma bupivacaine concentrations were measured in all patients from blood samples drawn after the insertion of the PA catheter (control) and at 5, 10, 15, 30, 45, 60, $90,120,180,240$ and 300 minutes after injection. The plasma concentration of bupivacaine was measured by reverse phase high-pressure liquid chromatography whose coefficient of variation within day was 4.9 per cent and between day was 6.0 per cent. $^{3}$

The study was terminated at the end of surgery at which time the patients were transferred to the recovery room and monitored until they were haemodynamically stable and motor function had returned.

All data are reported as mean \pm SD. Haemodynamic data were analyzed using Student's $t$ test with pooled estimate of variance and Bonferroni correction. Plasma concentration data were analyzed with one-way ANOVA for repeated measures and $\boldsymbol{P}<0.05$ was considered to be significant for all analyses.

\section{Results}

The patient characteristics are presented in Table I. The groups were demographically similar with the exception of the male:female ratio which was 10:0 in Group B and 6:4 in Group B + E. The patients in each group were taking a wide variety of cardiac medications which are listed in Table II. There were no significant differences between the groups in the maximum level of sensory block achieved. The average maximum level of sensory block was thoracic dermatome (T) 3.5 in Group $B$ (range $T_{2}-T_{8}$ ) and $T_{4.2}$ (range $T_{2}-T_{7}$ ) in Group $B+E$.

No significant differences between the groups were detected in the fluid needed to maintain the pulmonary

TABLE I Demographic data

\begin{tabular}{lll}
\hline & Group B & Group B $+E$ \\
\hline$n$ & 10 & 10 \\
Sex $(\mathrm{M} / \mathrm{F})$ & $10 / 0$ & $6 / 4$ \\
Age $(\mathrm{yr})$ & $68.0 \pm 7.5$ & $72.4 \pm 9.8$ \\
Height $(\mathrm{cm})$ & $167.8 \pm 12.4$ & $166.2 \pm 9.7$ \\
Weight $(\mathrm{kg})$ & $69.6 \pm 8.8$ & $68.4 \pm 13.2$ \\
BSA $\left(\mathrm{m}^{2}\right)$ & $1.77 \pm 0.16$ & $1.75 \pm 0.20$ \\
\hline
\end{tabular}

Mean \pm SD. 


\section{TABLE II Patient medications}

\begin{tabular}{lll}
\hline & Group B & Group B $+E$ \\
\hline Beta-adrenergic antagonists & 3 & 1 \\
Calcium channcl blocking drugs & 4 & 2 \\
Diuretics & 4 & 6 \\
Digoxin & 1 & 5 \\
Systemic nitrates & 2 & 4 \\
Dilantin & 2 & 1 \\
Aldomet & 0 & 2 \\
Quinidine, captopril & 1 (each) & 0 \\
Encainide, Clonidine & 0 & 1 (each) \\
\hline
\end{tabular}

TABLE III Fluid input and urine output

\begin{tabular}{lll}
\hline & $\begin{array}{l}\text { Fluid input } \\
(\mathrm{ml})\end{array}$ & $\begin{array}{l}\text { Urine output } \\
(\mathrm{ml})\end{array}$ \\
\hline $15 \mathrm{~min}$ & & \\
$\mathrm{~B}$ & $700 \pm 214$ & $113 \pm 105$ \\
$\mathrm{~B}+\mathrm{E}$ & $910 \pm 390$ & $117 \pm 140$ \\
$45 \min$ & & \\
B & $1250 \pm 350$ & $191 \pm 135$ \\
B $+\mathrm{E}$ & $1565 \pm 400$ & $219 \pm 187$ \\
\hline
\end{tabular}

Mean \pm SD. wedge pressure at control values or in urine output at either 15 or $45 \mathrm{~min}$ (Table III).

Haemodynamic data are shown in Table IV. No haemodynamic variables were significantly different between groups at control. Table $V$ shows the haemodynamic data at 15 and $45 \mathrm{~min}$ as a percentage of the control values. A significant difference between groups was detected in mean blood pressure (MBP), systemic vascular resistance (SVR) and cardiac output (CO) as a percentage of control at $15 \mathrm{~min}$ after epidural injection but not at $45 \mathrm{~min}$. No significant differences between groups were found for heart rate (HR) or pulmonary wedge pressure (PWP) as a percentage of control at either time interval.

Mean plasma bupivacaine concentrations for each group are presented in the Figure. Data from one patient in Group B and two patients in Group B + E were rejected using Dixon's criteria for outliers. ${ }^{4}$ None of these three patients experienced toxic symptoms. The remaining data, analyzed using a one-way ANOVA for repeated measures yielded a $P$ value of 0.08 . Power analysis of these data suggests that 16-18 patients per group are necessary to ensure a beta (power) of 0.80 , assuming an alpha of 0.05 and that the observed average standard

TABLE IV Haemodynamic data

\begin{tabular}{llllll}
\hline & $\begin{array}{l}H R \\
(\mathrm{bpm})\end{array}$ & $\begin{array}{l}\mathrm{MBP} \\
(\mathrm{mmHg})\end{array}$ & $\begin{array}{l}\mathrm{CO} \\
\left(\mathrm{L} \cdot \mathrm{min}^{-1}\right)\end{array}$ & $\begin{array}{l}S V R \\
\left(\mathrm{~d} \cdot \mathrm{s} \cdot \mathrm{cm}^{-5} \cdot 10^{-3}\right)\end{array}$ & $\begin{array}{l}P W P \\
(\mathrm{mmHg})\end{array}$ \\
\hline $\begin{array}{l}\text { Control } \\
\text { B }\end{array}$ & $71.8 \pm 9.5$ & $106.3 \pm 18.9$ & $4.62 \pm 1.58$ & $2.13 \pm 1.61$ & $15.0 \pm 6.2$ \\
B + E & $76.3 \pm 15.3$ & $104.2 \pm 18.2$ & $4.50 \pm 1.50$ & $1.82 \pm 0.41$ & $13.6 \pm 5.5$ \\
$15 \min$ & & & & & \\
B & $68.9 \pm 8.7$ & $99.6 \pm 19.2$ & $4.64 \pm 1.32$ & $1.80 \pm 0.85$ & $13.1 \pm 5.4$ \\
B + E & $78.3 \pm 15.3$ & $83.1 \pm 22.0$ & $5.81 \pm 2.07$ & $1.11 \pm 0.31$ & $11.3 \pm 3.8$ \\
$45 \min$ & & & & & \\
B & $62.7 \pm 7.8$ & $92.2 \pm 17.1$ & $4.58 \pm 1.01$ & $1.58 \pm 0.54$ & $12.9 \pm 3.2$ \\
B + E & $71.2 \pm 11.8$ & $86.0 \pm 21.5$ & $5.25 \pm 1.68$ & $1.30 \pm 0.47$ & $13.1 \pm 4.4$ \\
\hline
\end{tabular}

Mean \pm SD.

TABLE $V$ Haemodynamic data as percentage of control

\begin{tabular}{lrllll}
\hline & \multicolumn{1}{l}{ HR } & \multicolumn{1}{l}{ MBP } & CO & \multicolumn{1}{l}{ SVR } & \multicolumn{1}{l}{ PWP } \\
\hline 15 min & & & & & \\
B & $96.3 \pm 7.3$ & $94.5 \pm 15.8^{*}$ & $105.0 \pm 20.8^{*}$ & $91.6 \pm 19.2^{*}$ & $99.8 \pm 29.2$ \\
B + E & $104.0 \pm 17.4$ & $79.3 \pm 11.6^{*}$ & $130.8 \pm 23.0^{*}$ & $61.6 \pm 9.0^{*}$ & $79.4 \pm 20.5$ \\
& & & & & \\
45 min & & & & & \\
B & $87.7 \pm 7.6$ & $87.5 \pm 13.7$ & $107.8 \pm 35.5$ & $84.9 \pm 19.9$ & $101.3 \pm 23.9$ \\
B + E & $94.7 \pm 12.9$ & $82.4 \pm 14.1$ & $118.1 \pm 22.1$ & $71.3 \pm 16.4$ & $92.2 \pm 25.4$ \\
\hline
\end{tabular}

Mean \pm SD.

* $P<0.05$ between groups. 


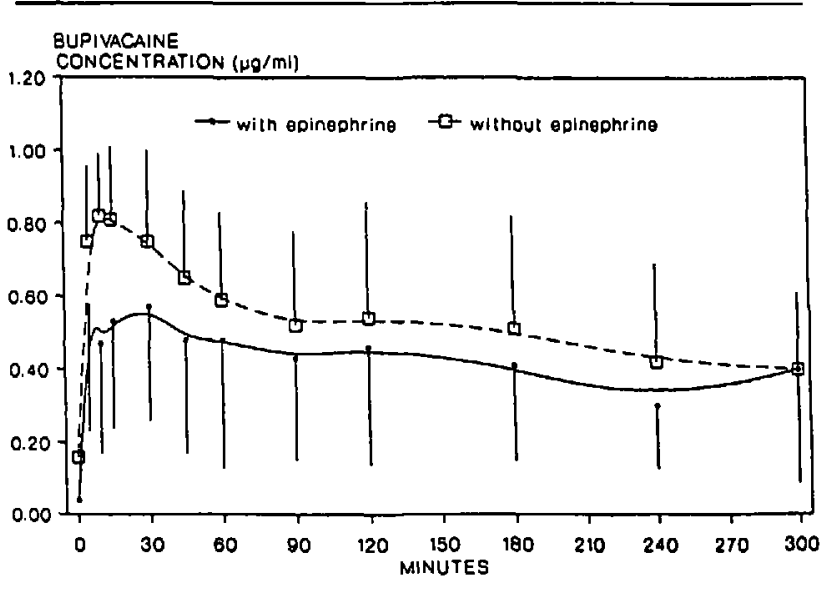

FIGURE Average plasma bupivacaine concentration versus time after epidural injection. All subjects received $12 \mathrm{ml}$ of 0.75 per cent bupicavaine without (Group B, $n=9$ ) or with (Group B $+\mathrm{E}, n=8$ ) cpinephrine, $5 \mu \mathrm{g} \cdot \mathrm{ml}^{-1}$.

deviation of the concentration data is of the same order of magnitude.

The measured peak plasma concentration of bupivacaine and the time to achieve this plasma concentration were determined for each patient and averaged over both groups. The peak plasma concentration of bupivacaine was $0.86 \pm 0.20 \mu \mathrm{g} \cdot \mathrm{ml}^{-1}$ in Group B and $0.64 \pm 0.33$ $\mu \mathrm{g} \cdot \mathrm{ml}^{-1}$ in Group $\mathrm{B}+\mathrm{E}(P=0.05)$. The time to achieve peak concentration was $16.1 \pm 11.2 \mathrm{~min}$ in Group $\mathrm{B}$ and $33.7 \pm 20.1 \mathrm{~min}$ in Group B + E $(P<0.05)$.

\section{Discussion}

This study demonstrated that the addition of epinephrine, $5 \mu \mathrm{g} \cdot \mathrm{ml}^{-1}$, to bupivacaine, 0.75 per cent, was associated with a lower MBP and SVR and a higher CO $15 \mathrm{~min}$ after epidural injection than bupivacaine, 0.75 per cent, alone. Furthermore, these haemodynamic differences were not statistically significant by $45 \mathrm{~min}$ after epidural injection.

The two groups showed no significant differences in demographic variables including age, height, weight and BSA. Using data from a large series of patients who have presented for peripheral vascular surgery, ${ }^{5}$ the male: female composition of Group B is significantly different from that expected $(P<0.05)$ but is unlikely to be a significant factor in the observed difference in haemodynamic responses between groups. The two groups also differed in cardiac medication profiles although this was not reflected in control haemodynamic measurements. More patients in Group B + E were taking digoxin, which had been prescribed for the treatment of heart failure and, in one case, to control the ventricular response to atrial fibrillation.

The haemodynamic effects of epidural epinephrine have been reported by Bonica et al. ${ }^{6}$ in young, healthy male volunteers. In their study lidocaine, two per cent, with and without epinephrine, $5 \mu \mathrm{g} \cdot \mathrm{ml}^{-1}$, was given sequentially to 12 subjects. Greater decreases in SVR and MBP and a greater increase in CO were demonstrated after lidocaine with epinephrine with the maximum effects noted at $15 \mathrm{~min}$ after epidural injection, but, in contrast to our results, these changes were accompanied by a significant increase in HR. The difference in haemodynamic effects was attributed to beta adrenergic stimulation caused by systemic absorption of small amounts of epinephrine, which was confirmed by subsequent direct measurement of the haemodynamic effect of plain epidural epinephrine, $100 \mu \mathrm{g}$. The timing of these measured changes prompted a similar timing of observations in the present study.

Delayed absorption of local anaesthetic by epidural epinephrine can result in lower plasma anaesthetic concentrations. The haemodynamic effects of systemic local anaesthetic are drug- and dose-dependent. ${ }^{7}$ Experimental evidence indicates that low plasma bupivacaine concentrations would produce a mild negative inotropic effect with a small increase in SVR. ${ }^{8}$ There is no evidence, however, to suggest that a difference of $0.3-0.4 \mu \mathrm{g} \cdot \mathrm{ml}^{-1}$, which was the maximum found between the two study groups, is sufficient to explain the observed haemodynamic differences.

Bromage has postulated that epidural anaesthesia with solutions containing epinephrine results in more profound sympathetic neuroblockade than epidural anaesthesia with solutions of plain local anaesthetic. ${ }^{9}$ Experimental evidence using skin-conductive response indicates that sympathetic block during spinal anaesthesia can be much lower in segmental level and of shorter duration than sensory block. ${ }^{10}$ The uncoupling of sympathetic and sensory block in epidural anaesthesia is supported by one study in which two of ten subjects failed to develop evidence of sympathetic blockade despite sensory analgesia to $T_{1}{ }^{11}$

The haemodynamic effects of sympathetic block are complex and depend, among other factors, on the level of block and the volume status of the patient. ${ }^{12} \ln$ the study, pulmonary wedge pressure was kept constant with fluid infusion, allowing a comparison between patients with equivalent preload. Under this condition, sympathetic blockade, which decreases tone in resistance vessels, will lead to a decrease in SVR. This in turn may increase cardiac output, especially in patients with cardiac disease. This is qualitatively the same effect produced by beta adrenergic stimulation from small amounts of systemically absorbed epinephrine. Although the study demonstrated an effect on the cardiovascular system associated with epidural epinephrine, it is not possible to determine whether this was a direct effect of absorbed epinephrine or 
an indirect effect based on differential sympathetic blockade.

Heart rate changes observed in the study were minimal. The failure to observe any significant increase in heart rate in the group receiving epidural epinephrine can be interpreted as evidence of the indirect effect of epidural epinephrine on sympathetic blockade. As sympathetic block rises to the $T_{1-4}$ level, cardiac sympathetic outflow and reflexes will be blocked with resultant decreases in heart rate and vagal predominance. ${ }^{12}$ This effect will compete with the positive chronotropic effect of direct beta adrenergic stimulation. The net result is an unpredictable change in heart rate depending on which effect is predominant at a given time.

Based on the patieni's history and examination of the ECG there is a 55 per cent chance of coronary artery disease being present in patients undergoing peripheral vascular surgery. ${ }^{5}$ However, only 8.5 per cent of 1,000 patients scheduled for peripheral vascular surgery were shown by angiography to have normal coronary arteries. ${ }^{5}$ Even if not suspected on clinical or electrophysiological grounds, coronary artery disease is common in this patient population. The lower SVR and MBP in those patients receiving epidural epinephrine, though transient, may have an important negative impact on myocardial oxygenation. The use of fluid infusion to restore haemodynamic variables to pre-epidural values may be associated with fluid overload, especially in the postoperative period, when the sympathetic blockade wears off and SVR increases. In this study no patient developed symptoms or ECG signs of ischaemia or failure during the operative or immediate postoperative periods. Vasopressor agents can be used to restore MBP, but recent evidence suggests that phenylephrine used for this purpose is associated with regional myocardial dysfunction characteristic of ischaemia. ${ }^{13}$ However, decreases in SVR and MBP can improve myocardial oxygenation in some patients with coronary artery disease by reducing afterload, thus outweighing the potentially deleterious effects on myocardial perfusion pressure. It is not possible to predict, however, which patients will benefit and which will be harmed by these cardiovascular changes.

The peak plasma concentration of bupivacaine in this study was lower in Group B + E and was achieved in a shorter time than in Group B. The results are consistent with those reported by Ray ${ }^{14}$ and Burm, ${ }^{15}$ but at variance with those obtained in healthy elderly patients. ${ }^{16}$ This may be due to the difference in the method of determining plasma bupivacaine concentration, but it is also possible that different concentrations of epidural bupivacaine produce different peak plasma concentrations in these elderly patients for the same total dose. Some evidence exists for such an effect in mepivicaine absorption after various regional blocks. ${ }^{17}$ In addition, plasma concentrations of lidocaine are elevated in patients with heart failure relative to control subjects after the same dose. ${ }^{18}$ It is possible that the patients in our study had altered pharmacokinetics as a function of their chronic heart disease, resulting in greater plasma bupivacaine concentrations than those reported in the elderly but healthy subjects of Veering et al. ${ }^{16}$

The delay in the time to peak bupivacaine concentration in Group B + E can be explained by the local vasoconstrictor action of epidural epinephrine and is consistent with the shapes of the concentration profiles shown in the Figure. Epidural epinephrine appears to delay systemic absorption of epidural bupivacaine and produces a concentration profile with a broad plateau rather than a distinct peak.

In conclusion, it has been demonstrated that the addition of epinephrine, $5 \mu \mathrm{g} \cdot \mathrm{ml}^{-1}$, to epidural bupivacaine, 0.75 per cent, when compared with plain epidural bupivacaine, 0.75 per cent, is associated with a greater decrease in mean blood pressure and systemic vascular resistance and a greater increase in cardiac output, but no difference in heart rate. Though transient, these added disturbances in myocardial oxygen balance are potentially harmful in elderly patients with cardiac disease, particularly if associated with intravascular volume overload or the administration of vasoconstrictors. Combined with the observation that epinephrine added to epidural bupivacaine does not alter the duration ${ }^{19}$ or the quality ${ }^{20}$ of sensory block, the results suggest that epinephrine need not be routinely added to bupivacaine when providing epidural anaesthesia for peripheral vascular surgery. Furthermore, epidural epinephrine alters the absorption of epidural bupivacaine by delaying the peak plasma concentration and by reducing the magnitude of this peak.

\section{Acknowledgements}

The support and cooperation of Winthrop Laboratories in the execution of this study is gratefully acknowledged. We would also like to thank Sherville Walrond, Lea Smilovici and Joanne Turner for their secretarial assistance.

\section{References}

1 Damask MC, Weissman C, Barth A et. al. General versus epidural - which is the better anesthetic technique for femoral-popliteal bypass surgery? Anesth Analg 1986; 65: S39.

2 Stanton-Hicks $M D$. Cardiovascular effects of extradural anaesthesia. Br J Anaesth 1975; 47: 253-63.

3 Ha HR, Funk KB, Gerber HR, Folath F. Determination of bupivacaine in plasma by high-performance liquid chromatography. Anesth Analg 1984; 63: 448-50. 
4 Snedecor GW, Cochran WG. Statistical Methods. Iowa City: Iowa State Univ. Press, 1980.

5 Hertzer NK. Cardiac risk factors in peripheral vascular surgery. In: Estafanous FG (Ed.). Anesthesia and the Heart Patient, Toronto: Butterworth's, 1989: 174.

6 Bonica JJ, Akamatsu TJ, Berges PU, Morikawa K, Kennedy WF. Circulatory effects of peridural block II - effects of epinephrine. Anesthesiology 1971; 34: 514-22.

7 Covino BG. Clinical pharmacology of local anesthetic agents. In: Cousins MJ, Bridenbough PO (Eds,).

Neural Blockade in Clinical Anesthesia and Management of Pain, 2nd ed., New York: JB Lippincott, 1988: 123-9.

8 Block A, Covino BG. Effect of local anesthetic agents on cardiac conduction and contractility. Reg Anesth 1982; 6: 55.

9 Bromage PR. Epidural Analgesia. Philadelphia: WB Saunders, 1978.

10 Bengtsson $M$. Changes in skin blood flow and temperature during spinal analgesia evaluated by laser doppler flowmetry and infra-red thermography. Acta Anaesthesiol Scand 1984; 28: 625-30.

11 Bonica JJ, Berges $P U$, Morikawa $K$. Circulatory effects of peridural block I - effects of levels of analgesia and dose of lidocaine. Anesthesiology 1970; 33: 619-26.

12 Cousins MJ, Bromage PR. Epidural Neural Blockade. In: Cousins MJ, Bridenbough PO (Eds.). Neural Blockade in Clinical Anesthesia and Management of Pain, 2nd ed., New York: JB Lippincott, 1988: 279.

13 Smith JS, Roizen MF, Calahan MK et al. Does anesthetic technique make a difference? Augmentation of systolic blood pressure during carotid endarterectomy: effects of phenylephrine versus light anesthesia and of isoflurane versus halothane on the incidence of myocardial ischemia. Anesthesiology 1988; 69: 846-53.

14 Raj PP, Rosenblatt R, Miller J, Katz RL, Carden E. Dynamics of local anesthetic compounds in regional anesthesia. Anesth Analg 1977; 546: 110-7.

15 Burm AG. Pharmacokinetics and clinical effects of lidocaine and bupivacaine following epidural and subarachnoid administration in man. PhD Thesis, University of Leiden, 1985.

16 Veering BTh, Burm AG, vanKleef JW, Hennis PJ, Spier$d i j k J$. Epidural anesthesia with bupivacaine: effects of age on neural blockade and pharmacokinetics. Anesth Analg 1987; 66: 589-93.

17 Tucker GT, Moore DC, Bridenbough PO, Bridenbough $L D$, Thompson GE. Systemic absorption of mepivicaine in commonly used regional block procedures. Anesthesiology 1972; 37: 277-87.
18 Thompson PD, Melmon KL, Richardson JA et al. Lidocaine pharmacokinetics in advanced heart failure, liver disease and renal failure in humans. Ann Intem Med 1973; 78: 499-508.

19 Keir L. Continuous cpidural analgesia in prostatectomy: comparison of bupivacaine with and without adrenaline. Acta Anaesthesiol Scand 1974; 18: 1-4.

20 Sinclair $C J$, Scott $D B$. Comparison of bupivacaine and etidocaine in extradural blockade. Br J Anacsth 1984; 56: 147-53. 